\title{
Reflexões sobre a Regulamentação
}

\author{
Leonardo Fernando Cruz Basso \\ Marcelo Roque da Silva
}

\section{RESUMO}

O objetivo deste trabalho, que utiliza o método de pesquisa bibliográfica e na Internet, foi apresentar as três teorias defensoras da desregulamentação de monopólios e oligopólios: crítica de Demsetz, teoria dos mercados contestáveis e teoria da captura. Ainda, alerta para problemas, custos e dificuldades relacionados à regulamentação, bem como estuda alguns casos de indústrias, onde o fenômeno já ocorreu, com o que alimenta o debate sobre este aspecto econômico, no Brasil e em outros países. Concluiu-se que é necessária muita reflexão na regulamentação de indústrias, por que, além de haver opções menos danosas do ponto de vista da competição e, portanto, mais pró-consumidores, a regulamentação, defendida como proteção contra preços abusivos (monopolistas), entre outros problemas, pode tornar-se uma forma de perpetuação de monopólios; pode fixar preços e tarifas em níveis elevados, pelo conluio entre regulamentados e regulamentadores; é cara e de difícil execução e monitoramento. Eis por que a desregulamentação, apesar de pouco debatida sua importância, pode constituir uma política susceptível de implementação em muitas situações.

Palavras-chaves: desregulamentação; competição; monopólio.

\begin{abstract}
The goal of this work was to present the three theories that defend the monopoly and oligopoly deregulation: Demsetz critic, theory of contestable markets and theory of capture. This was achieved using bibliographic and Internet research. We support the debate concerning this economical aspect, in Brazil and other countries, alerting about problems, costs and difficulties related to the regulation and also studying some industrial cases where the deregulation has already taken place. We concluded that much reflection is necessary when dealing with industrial regulation since there are less damaging options from the point of view of competition - and therefore more pro-consumers. The regulation, defended as a protection against abusive (monopolist) prices, among other problems may become a way of monopoly perpetuation; it could set prices and taxes in high levels, by collusion between regulated and regulators; it is expensive, difficult to execute and to monitor. The deregulation, despite its importance, is relatively not much debated, even though it could be a politic to be implemented in several situations.
\end{abstract}

Key words: deregulation; competition; monopoly. 


\section{INTRODUÇÃO}

A desregulamentação de indústrias, antes diretamente controladas pelo Governo, possui implicações sociais importantes, como evitar o provável conluio entre os produtores e os regulamentadores em prejuízo dos consumidores, caso exposto pela chamada teoria da captura, o que eleva os preços e os lucros das empresas, reduzindo, assim, o bem-estar da população. Evita também a própria regulamentação, que é dispendiosa e difícil de ser monitorada.

A regulamentação pode ainda levar à ocorrência de outros problemas, como conluio, corrupção e perpetuação dos monopólios em condições artificiais, pela adoção de barreiras ao ingresso de novas firmas no mercado. As tarifas praticadas pelas empresas, quando fixadas pelo Governo em níveis baixos, podem reduzir perigosamente o volume necessário de novos e vitais investimentos, e ainda acarretar a falência destas firmas. O controle governamental via regulamentação também deve, necessariamente, ser levado a cabo com um grau insuficiente de informação a respeito da empresa em foco (principal-agent theory).

Sendo assim, a partir principalmente da década de 70, estudos econômicos foram realizados no sentido de criticar a regulamentação e propor sua extinção. É o caso da teoria da captura, da teoria dos mercados contestáveis e da crítica de Demsetz. Com base nestas três teorias, mas principalmente na segunda, vem ocorrendo a desregulamentação de grandes indústrias nos Estados Unidos. Este fato sublinha a importância de se chegar a obter uma maior disseminação de tais teorias nos meios acadêmicos e sociais brasileiros.

A desregulamentação, nos casos estudados nos Estados Unidos, vem apresentando resultados positivos como redução dos preços, aumento da pesquisa tecnológica, incremento da competição pela elevação no número de firmas atuando no mercado e aumento da eficiência, apesar de haver tendência à reconcentração.

A importância científica existente em se abordar o tema da desregulamentação de monopólios (e oligopólios) está relacionada principalmente à possibilidade de difundir este assunto nos meios acadêmicos brasileiros, e engendrar maior discussão sobre as vantagens que o Brasil, eventualmente, pode obter, se optar por desregulamentar algumas de suas indústrias, desde que as características destas assim o permitam, de acordo com as teorias citadas. 


\section{A Regulamentação}

Muitos monopólios fazem parte dos serviços chamados de utilidade pública. Alguns exemplos são transmissão e distribuição de energia elétrica, fornecimento de água encanada, sistema de esgotos etc. A grande maioria deles é formada por monopólios naturais, pois as empresas que os fornecem incorrem em situações de mercado, onde há economias de escala tais, que apenas uma única empresa é capaz de suprir a demanda pelo produto ou serviço, com custos inferiores aos que ocorreriam, se houvesse mais de uma empresa atuando no mercado.

De acordo com Rosen (1995), o monopólio irá produzir a quantidade Xm ao preço Pm na Figura 1. Nesse ponto, em que o custo marginal cruza com a receita marginal, se dá a maximização do lucro do monopolista. Nota-se que a quantidade Xm é bastante baixa e o preço Pm, por seu lado, é consideravelmente elevado. Isso finda por reduzir o bem-estar da sociedade em relação ao que ela obteria, se a produção se desse em nível ótimo, de concorrência perfeita, indicado pela quantidade $\mathrm{X}^{*}$ e pelo preço $\mathrm{P}^{*}$, na figura. Nota-se que o preço $\mathrm{P}^{*}$ é muito inferior ao preço chamado de monopólio, $\mathrm{Pm}$, e a quantidade $\mathrm{X}^{*}$ também é muito maior do que a quantidade de monopólio, $\mathrm{Xm}$.

\section{Figura 1: Monopólio Natural, Concorrência Perfeita e Produção no Nível do Custo Médio}

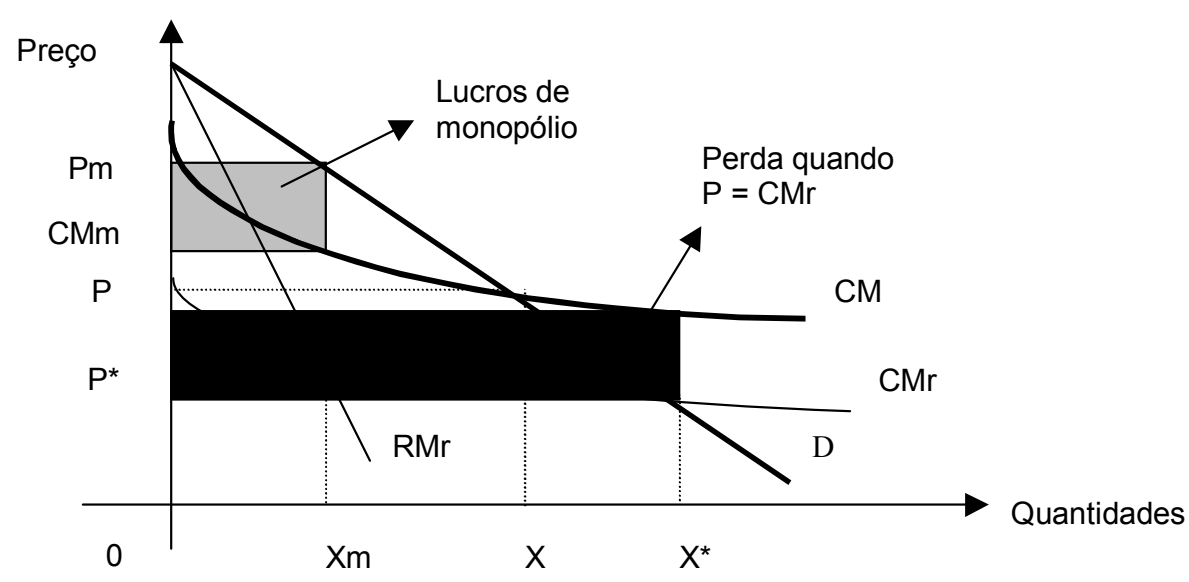

No ponto de concorrência perfeita ocorre um prejuízo para a empresa, indicado pelo retângulo maior e mais escuro. O Governo, nesse caso, pode obrigá-la a atuar com esses níveis de preço e produção através da regulamentação e, para cobrir o prejuízo, impor à sociedade uma tarifa (sistema conhecido como marginal 
cost pricing with lump taxes). Ou pode utilizar o sistema de tarifa dupla (two-part tariff), que muitos economistas aconselham, onde é cobrada uma taxa de ingresso a quem desejar adquirir o bem, vendido a quem pagar esta taxa, ao preço de concorrência perfeita. Nos Estados Unidos, o método mais utilizado para regulamentar as empresas monopolistas é o chamado average cost pricing, ou seja, preço no nível do custo médio. Na Figura 1 essa produção pode ser visualizada ao preço $\mathrm{P}$ e à quantidade $\mathrm{X}$. A empresa produzindo nesse nível não obtém lucro, mas também não incorre em prejuízo.

Como informa Leftwich (1983), há três maneiras possíveis para que os governos regulamentem monopólios, como se explicita em seguida.

\section{. Controle direto sobre o preço}

É o melhor dos três tipos de regulamentação descritos, pois reduz os preços e os lucros do monopolista, ao mesmo tempo que aumenta as quantidades produzidas, elevando o bem-estar dos consumidores.

\section{Figura 2: Regulamentação de um Monopólio pelo Controle Direto sobre o Preço}

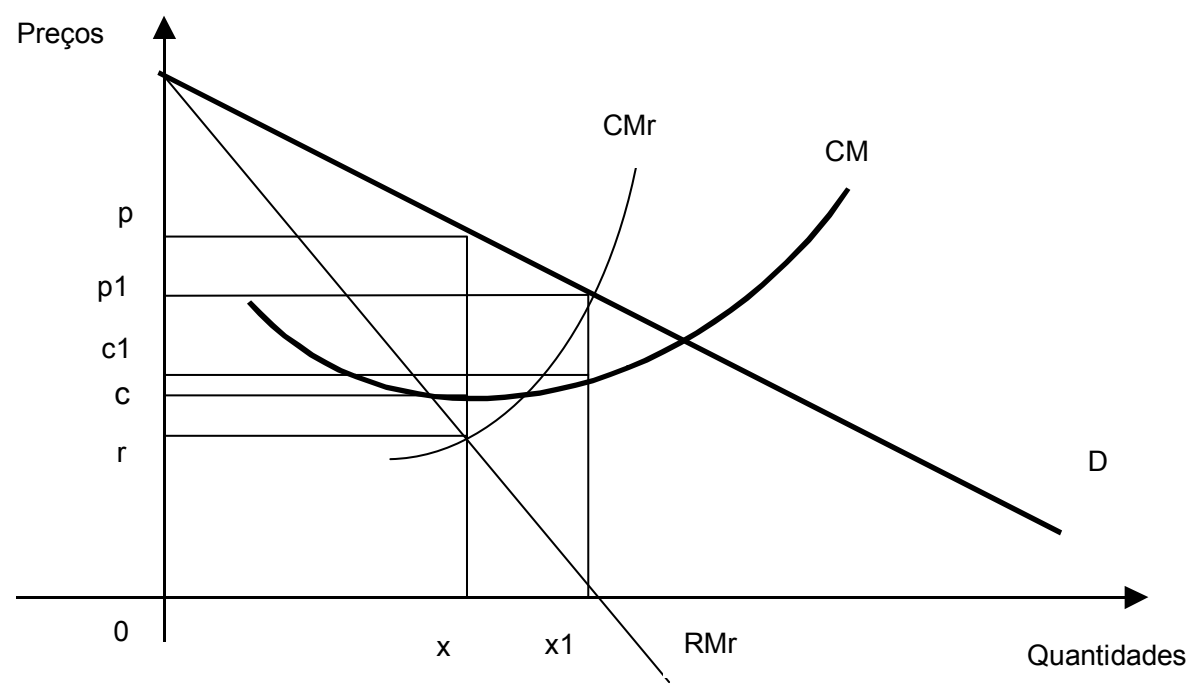

Na Figura 2, pode ser vista a maximização usual do lucro do monopolista, ao preço $p$, e também o efeito de uma fixação de preço por parte do Governo $(\mathrm{p} 1)$, que leva a uma maior produção $(\mathrm{x} 1)$ em relação à produção anterior $(\mathrm{x})$. $\mathrm{O}$ novo lucro será $(\mathrm{x} 1)(\mathrm{c} 1 \mathrm{p} 1)$. 


\section{. Imposto sobre as unidades produzidas pela empresa}

Apesar de reduzir os lucros da empresa monopolista, termina por elevar seus preços e reduzir a sua produção.

\section{Figura 3: Imposto Fixo sobre a Produção do Monopolista}

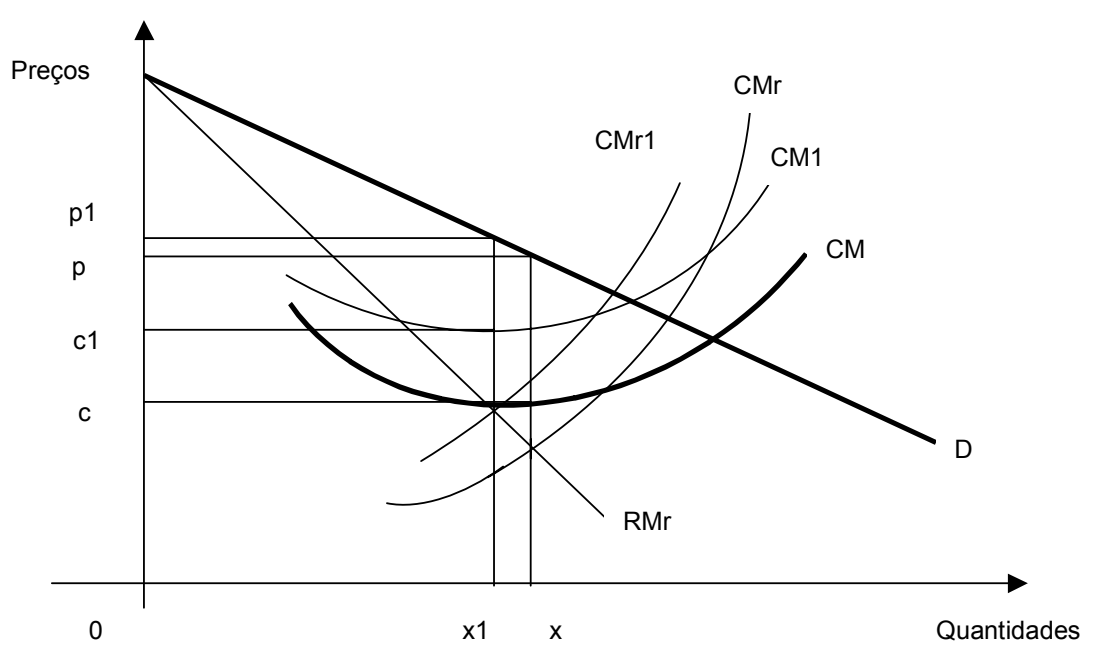

A empresa detentora do monopólio irá reduzir sua produção, do ponto x para o ponto $\mathrm{x} 1$ e também elevará seu preço, do nível $\mathrm{p}$ para o nível $\mathrm{p} 1$. Dessa forma, ela irá conseguir transferir à sociedade uma parcela do imposto, cobrado pelo Governo sobre sua produção, por meio dos órgãos regulamentadores cabíveis. Mesmo assim seu lucro, $(\mathrm{x} 1)(\mathrm{c} 1 \mathrm{p} 1)$, será inferior ao verificado anteriormente à implementação do imposto, $(\mathrm{x})(\mathrm{cp})$.

Por determinar menor produção e maiores preços, este tipo de tributação reduz o bem-estar da sociedade.

\section{. Imposto global sobre a produção da firma}

Ao contrário do imposto anterior, que significava um custo variável para a firma, este significa um custo fixo. Na Figura 4 podemos verificar que não há alteração na quantidade produzida após a aplicação do imposto, assim como também os preços praticados permanecem inalterados. $\mathrm{O}$ monopolista não pode transferir ônus da taxação à sociedade e seus lucros caem de (x)(cp) para $(x)(c 1 p)$. 


\section{Figura 4: Imposto Global como Instrumento de Controle sobre o Monopólio}

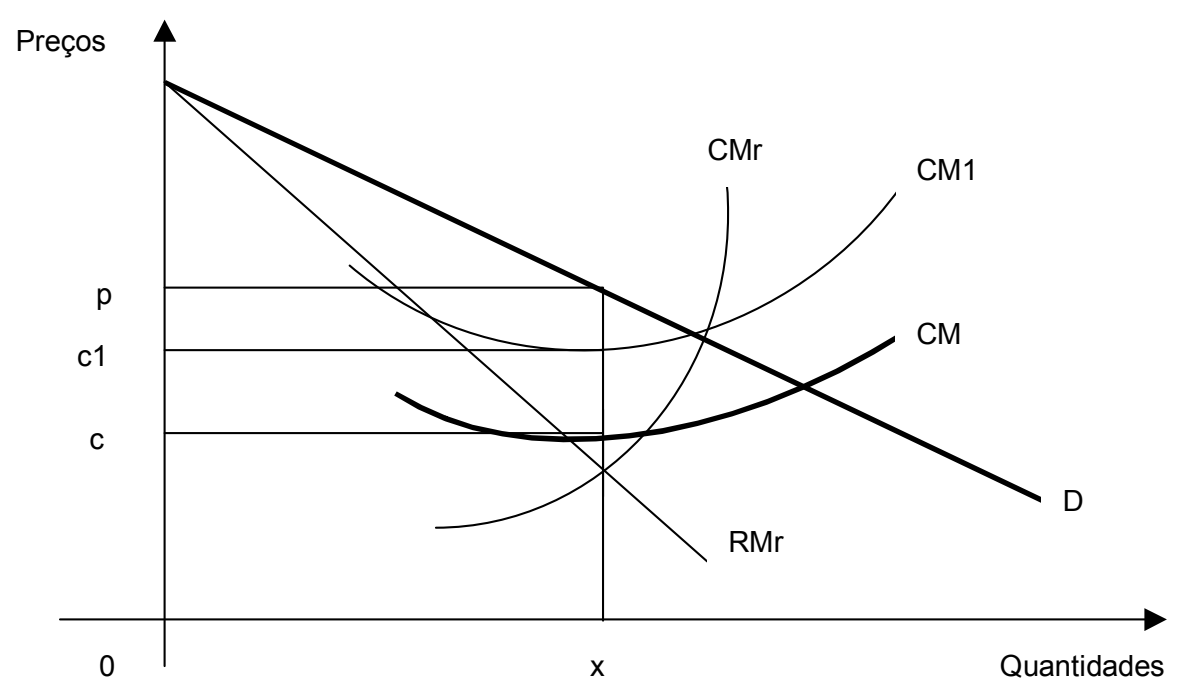

É também importante saber que, no intuito de se regulamentarem os monopólios, o maior problema enfrentado é a falta de informação. "A assimetria de informação está no coração da economia da regulamentação. Se o Governo e os gerentes das firmas tivessem acesso à mesma informação sobre as condições da indústria e o comportamento da firma, o problema da regulamentação poderia ser resolvido simplesmente dirigindo os gerentes para a implementação do plano socialmente ótimo, dadas as informações [comuns] à disposição. Na realidade, todavia, os gerentes são muito mais bem informados sobre as condições da indústria do que os donos das firmas e os regulamentadores, e seu comportamento pode ser monitorado apenas de forma imperfeita" (Vickers e Yarrow, 1997, p. 99).

\section{As teorias e Avanços Recentes na Questão da Desregulamentação dos Serviços de Utilidade Pública}

Os serviços de utilidade pública são essenciais à qualidade de vida da população e às empresas que os utilizam como insumos em sua produção. Economicamente, como foi dito antes, sua principal característica, em sua maioria, é serem monopólios naturais. Sendo assim, se forem fornecidos por mais de uma empresa, o custo médio para cada uma delas poderá ser superior ao verificado para apenas uma. 
Isso implica custos decrescentes, ou economias de escala, e a impossibilidade física de existir mais de uma firma na prestação do serviço.

No caso de a concorrência se efetivar, a tarifa provavelmente não será suficiente para gerar novos e indispensáveis investimentos. O tempo tem mostrado que, se na prestação destes serviços houver concorrência e se existir monopólio natural, o resultado natural desse processo é a falência de todas as firmas, menos uma. $\mathrm{O}$ termo monopólio natural possui este nome por ser o resultado natural do processo de concorrência neste caso.

Sendo os serviços de utilidade pública monopólios naturais e essenciais à população, surgiu uma teoria, chamada teoria do monopólio natural, que prega a regulamentação, pelo Governo, de todos os monopólios naturais, no intuito de evitar o abuso do poder de mercado possuído por tais firmas.

A regulamentação, como afirmado anteriormente, apresenta diversos problemas: pode ser a causa de perpetuação de monopólios em condições artificiais, pela adoção de barreiras ao ingresso de novas firmas no mercado; é dispendiosa e de difícil monitoração; e pode engendrar conluio e corrupção. Tarifas fixadas a baixos níveis podem ainda levar a empresa controlada à falência.

Os Estados Unidos são o país que era, até poucos anos atrás, praticamente o único caso de produção privada extensiva de serviços de utilidade pública. Neste país têm-se desenvolvido bastante o debate das modernas teorias favoráveis à desregulamentação deste tipo de serviço; já foram desregulamentados os setores de linhas aéreas, transporte rodoviário de carga, telecomunicações e energia elétrica.

Os estudos desses casos mostram que alguns benefícios foram alcançados com o processo. Por exemplo, uma vez que o Governo norte-americano eliminou as barreiras à entrada, houve significativa elevação no número de empresas concorrendo nos respectivos mercados. Na área de telecomunicações, verificou-se tendência à redução nos preços e aumento de pesquisa na área de tecnologia aplicada à produção. Pode ser afirmado, de modo geral, que a concorrência é intensificada, quando ocorre desregulamentação em determinado mercado (Farina e Schembri, 1990).

Nos Estados Unidos, informa o jornal The New York Times (1999), o primeiro caso de ação governamental contra uma empresa, por prática anticompetitiva, desde a implementação, em 1978, da desregulamentação da indústria de linhas aéreas, se deu em maio de 1999, com uma ação contra a American Airlines. A empresa foi acusada de baixar tarifas e adicionar vôos, na tentativa de expulsar outras empresas competidoras que cobravam tarifas baixas. 
É interessante notar que o setor de linhas aéreas americano passou por 21 anos de atividade desregulamentada sem nenhuma necessidade de intervenção do Governo no intuito de coibir atividades anticompetitivas por parte das empresas. Isso demonstra haver coerência no ato de desregulamentar certas indústrias, com base na crença de que a competição potencial, assim como ela é prescrita pela teoria dos mercados contestáveis, é suficientemente forte para exercer um controle sobre a indústria, sem que haja a necessidade da intervenção governamental.

As indústrias desregulamentadas nos Estados Unidos não fazem parte daquelas consideradas monopólios naturais. Tomemos o caso do setor elétrico, serviço de utilidade pública, para o qual a maioria dos economistas concorda a respeito da existência de monopólio natural, pelo menos em duas de suas três etapas: a transmissão e a distribuição. Na terceira etapa, a geração, realmente pode haver competição. $\mathrm{O}$ argumento mais utilizado para justificar a regulamentação dessa indústria é exatamente a existência de monopólio natural; mas há quem acredite que em nenhuma das três etapas da indústria isso de fato ocorra.

"Investigações dos economistas encontraram pouca evidência de que o negócio de eletricidade tenha 'naturalmente' adquirido o status de monopólio, anteriormente ao advento das public utility commissions, o que implica que a rede 'monopolística' é mais um produto artificial da regulamentação do que da eficiência econômica ou da inevitabilidade de mercado. De fato, as duas principais características dos monopólios naturais, altos custos fixos e economias de escala, estão amplamente ausentes nas modernas empresas de serviços de utilidade pública, sugerindo que a rede é vulnerável à competição. É interessante notar que as poucas comunidades que já têm a possibilidade de escolher seus provedores de eletricidade, cada um deles com sua própria rede separada, pagam tarifas abaixo das médias regionais [...] Como a regulamentação de tarifas é incapaz de controlá-las, e como a transmissão e a distribuição de eletricidade provavelmente não são monopólios naturais realmente, reformas reais devem ser dirigidas, não à reinvenção da regulamentação, mas à sua eliminação de fato" (Cato Institute, 19--).

Se é verdade que a indústria de eletricidade não é monopólio natural em nenhuma de suas três etapas, fato bastante discutível principalmente em relação à transmissão, mas também à distribuição, a atividade não necessitaria ser regulamentada. Dada a discrepância de opiniões, este é um claro exemplo de quão discutível é a existência ou não de monopólios naturais em muitas indústrias.

Por outro lado, inovações tecnológicas, modificadas as características das indústrias, podem reduzir, ou eventualmente eliminar o seu caráter de monopólio natural. É o caso, por exemplo, da indústria elétrica, cuja característica de mono- 
pólio natural vem sendo significativamente alterada como resultado de mudanças tecnológicas na área de geração. Atualmente, novas possibilidades de produção de energia com pequenas unidades geradoras têm conduzido ao aumento da competição no setor. Além disso, novas invenções têm surgido, possibilitando eliminar problemas como gargalos nos setores de transmissão e distribuição, fazendo com que a energia dessas novas e menores unidades geradoras encontrem cada vez menores obstáculos para chegar à ponta do consumo (Baer, 1997).

A desregulamentação de indústrias com grau muito elevado de regulamentação, é processo complexo e demorado. Deve-se atentar para não se eliminarem determinados tipos de regulação de forma precipitada e prematura, uma vez que, para implementar tal medida, é necessário que a competição já esteja fortemente atuante. Além disso, é necessária a vigilância por parte do Governo, pois a desregulamentação, sozinha, não leva indubitavelmente a um mercado competitivo, o que reforça o papel dos órgãos antitrustes.

Nos Estados Unidos, a indústria elétrica vem sendo desregulamentada há alguns anos. Os antigos monopólios têm sido amplamente removidos. A competição é considerada a melhor forma para se controlar o poder de mercado de algumas empresas. No período imediatamente anterior a esse processo, os empresários do setor de geração alegavam que não mais lhes seria possível, devido à desregulamentação, recuperar o montante de dinheiro gasto ao longo décadas de investimento. Havia o temor de que, após o processo se efetivar, ocorresse um trauma financeiro no setor, com falências sendo um resultado comum.

Com o passar de alguns poucos anos, a realidade da indústria, agora desregulamentada, tem-se mostrado muito mais tranquilizadora. Os temores não se concretizaram e o setor está crescendo. As ações das antigas usinas valorizaram-se, o que vem atraindo novos investidores para a indústria. Novas usinas estão sendo construídas. A geração de energia elétrica está se expandindo no país, com mais de 50.000 megawatts de incremento à atual produção sendo previstos para os próximos anos, significando um aumento de cerca de $6 \%$ em relação à atual capacidade geradora (Oppel Jr., 2000).

O fim dos monopólios naturais, por efeito de evoluções tecnológicas, e a não existência de monopólios naturais reais, como crêem alguns economistas, não são os únicos argumentos em favor do fim da regulamentação. Nas últimas décadas, movimentos contestatórios têm surgido, apresentando argumentação contrária à da idéia, até então vigente, a favor da regulamentação dos monopólios. Alguns destes argumentos afirmam, por exemplo, que a regulamentação seria desnecessária e outros afirmam que seria prejudicial. Destas teorias, as mais famosas são as apresentadas a seguir: a crítica de Demsetz, a teoria dos mercados contestáveis e a teoria da captura. 
Iremos mostrar estas novas formulações principalmente por acreditarmos que elas poderão ser úteis e influenciar a administração pública de países que, a partir da conclusão de seus processos de privatização, a exemplo do Brasil, muito provavelmente terão, no intervalo de alguns poucos anos, estes setores monopolistas de suas economias nas mãos da iniciativa privada. O próximo passo pode ser a desregulamentação.

\section{Crítica de Demsetz}

A crítica de Demsetz, também é conhecida como proposta Chadwick-Demsetz, pois foi Edwin Chadwick, um reformador social vitoriano, quem primeiro a apresentou. Mais tarde ela foi desenvolvida por Demsetz e apresentada em seu famoso escrito Why Regulate Utilities?, ou seja, Por que Regulamentar os Serviços de Utilidade Pública?. Também é conhecida como sistema de franquia (franchising), onde ocorre a concessão do direito de exploração para determinada atividade.

Nele, o competidor que se comprometer a produzir aos preços mais baixos, ou ainda, oferecer o pacote mais interessante, no qual esteja incluído tanto preço quanto qualidade, receberá a concessão da franquia, de duração predeterminada. Este sistema funciona na prática em várias situações, principalmente na área privada, e elimina os problemas relativos à regulamentação, principalmente aqueles relacionados à falta de informação, pois será a competição que irá determinar quem virá a ser o produtor (Vickers e Yarrow, 1997).

De acordo com Johnson et al. (1996), o sistema de franquia tem por base uma forma de conquista do mercado, no caso um em situação de monopólio, na qual vigora uma espécie de leilão por esse mercado. As firmas interessadas em produzir, em condição de monopólio natural, por exemplo, apresentam suas propostas. A firma vencedora, no entanto, não deverá ter apresentado uma proposta de preço de monopólio, pois se o fizesse teria sido derrotada por outra empresa concorrente no leilão de ingresso ao mercado. Acredita-se que o preço da proposta vencedora se aproxime do concorrencial, por efeito da disputa.

Segundo a visão de Demsetz, existiria concorrência mesmo em situações de monopólio natural, consubstanciada pelo fato de que as empresas pretendentes têm, na prática, de concorrer umas com as outras para identificar e determinar qual delas vencerá e será a empresa produtora. A concorrência não existiria dentro do mercado, por se tratar de um monopólio, mas no momento de ingresso nesse mercado, o que traria poucas diferenças em termos de resultado final.

Em muitas indústrias, entretanto, esse tipo de leilão não poderia ocorrer. Ele seria mais comum e aplicável em serviços como o de concessão de televisão a cabo ou o de coleta de lixo urbano, por exemplo. Isso porque, para o esquema de 
Demsetz funcionar, é teoricamente necessária a existência de duas condições que não se verificam na maioria dos serviços de utilidade pública. Uma delas estabelece que o leilão deve ser necessariamente competitivo, não podendo ser viável, do ponto de vista econômico, o conluio entre as empresas concorrentes. A segunda condição exige que os insumos necessários à produção têm de estar à disposição de todas as empresas concorrentes, a preços concorrenciais.

Algumas críticas têm sido feitas à proposição de Demsetz: inicialmente argumenta-se a respeito da concorrência que, mesmo existindo, limitar-se-ia ao preço a ser cobrado, mas não à qualidade do serviço. Esta poderia ser alterada no decorrer do tempo e, nesse caso, seria necessário haver regulamentação da atividade. Também se discute a questão do prazo do contrato, necessariamente longo e complexo. Vários fatores teriam de ser especificados nos contratos, estabelecendo critérios para redução das tarifas por conta de melhorias em áreas como a tecnológica, de produtividade etc. Esta é uma visão dinâmica, por abranger um período de tempo - o contrato - enquanto a visão de Demsetz se dá sob um enfoque não-dinâmico, dado em um período de tempo pontual, o momento da concorrência para o mercado (Johnson et al., 1996).

Vickers e Yarrow (1997) apontam outros problemas. Um deles é o fato de que a empresa detentora da concessão, no momento em que esta for renovada, poderá fazer uso de vantagens estratégicas, quando competir com as demais empresas pelo direito à concessão. Por exemplo: a firma atualmente detentora da franquia (incumbente) pode ter conseguido, devido à sua experiência, reduzir seus custos operacionais. Isto tende a facilitar sua vitória na competição, e o conhecimento dessa possibilidade pode reduzir o número de empresas dispostas a competir pelo mercado.

A empresa incumbente também possui uma qualidade e uma quantidade de informações em relação à indústria, muito mais acuradas se comparadas às das firmas concorrentes. No caso de uma destas vencer, portanto, provavelmente terá pago mais do que deveria, problema chamado de maldição do vencedor (winner's curse). Esta é mais uma vantagem da firma detentora da concessão; assim como o problema das vantagens estratégicas, pode levar à redução da competição, fato negativo, pois uma das condições para o funcionamento do sistema é a existência de um leilão competitivo; um grande número de empresas concorrentes dificulta eventuais conluios.

Resta ainda o problema da transferência dos bens das empresas, quando uma sucede a outra na detenção do mercado. Se não houver sunk-costs - custos de impossível recuperação, caso a empresa abandone o negócio, como, por exemplo, trilhos de trem ou encanamentos subterrâneos de gás, a lógica obriga a que a empresa vencedora compre os bens da firma vencida, envolvidos na produção; 
mas a hipótese da não existência de sunk-costs é muito improvável na realidade. Além disso, é difícil realizar a avaliação desses bens. Assim, possivelmente a firma vencedora será obrigada a pagar, por não ter alternativa, um valor superior ao de mercado pelos bens da outra firma, ou então, a firma derrotada poderá se ver obrigada a vender os seus bens a preços inferiores ao seu real valor. Este problema é conhecido por assests handover. A diferença entre o preço pago ou cobrado e o preço justo aumenta na medida em que houver sunk-costs envolvidos (Vickers e Yarrow, 1997).

\section{Teoria dos Mercados Contestáveis}

A teoria dos mercados contestáveis (TMC) começou a ser delineada no começo da década de 70, mas ficou sendo mais conhecida principalmente após a publicação, por Baumol, Panzar e Willig (1982), do livro intitulado Contestable Markets and The Theory of Industry Structure.

Considera-se um mercado como sendo contestável, quando não houver barreiras à entrada nem custos à saída (sunk-costs) para as firmas que eventualmente nele desejem ingressar. As empresas nele atuantes não estão protegidas de eventuais entradas do tipo hit and run, firmas de fora que, atraídas por lucros extra-econômicos desse mercado, nele ingressem e obtenham lucro, isso ocorrendo antes que as firmas estabelecidas tenham tempo de sair do negócio ou mesmo alterar seu preços. Para que um determinado mercado seja contestável, é necessária a maior homogeneização possível dos produtos e o livre acesso aos métodos de produção para todos os produtores, que devem ter acesso à mesma tecnologia e possuírem a mesma demanda de mercado (Farina, 1990).

Como acontece com a crítica de Demsetz, mesmo em estruturas oligopolísticas e monopolísticas, incluindo monopólios naturais, com ocorrência de significativas economias de escala, pode ocorrer a contestabilidade. Em tais situações, afirma a TMC, uma empresa em posição de monopólio não poderia auferir lucros monopolísticos, porque, se o fizesse, estaria se sujeitando ao perigo de um ataque do tipo hit and run por parte de outras empresas. Isso é chamado de concorrência potencial. Dessa maneira, não haveria necessidade de se regulamentar estas indústrias, mesmo elas sendo monopólios naturais.

O próprio monopólio natural foi redefinido pelos estudiosos da TMC. Chegouse à conclusão de que uma empresa, produtora de vários bens ou serviços, poderia deter um monopólio natural, mesmo sem haver economias de escala no processo. Isso aconteceria, se tal empresa incorresse em custos menores em relação às demais, produtoras de bens ou serviços separadamente. A isso se chamou subaditividade de custos. Um monopólio natural teria lugar, nesse caso, quando 
uma firma possuísse a função de custo subaditiva no decorrer da região mais importante de sua produção (Farina, 1990).

Os sunk-costs, como foi dito, ocorrem quando há custos que devem ser cobertos, ainda que não haja produção. As firmas que possuem tais custos necessitam de um volume muito grande de capital, o qual é pouco móvel. Devido a estas características, tais mercados, onde se verifica a existência de sunk-costs, não podem ser contestáveis.

As firmas que incorrem em sunk-costs, ou as que demandam altas somas de capital, podem, entretanto, sofrer outro tipo de concorrência, a intermodal. Por exemplo, uma transportadora de óleo encanado pode sofrer concorrência intermodal do transporte do produto, óleo, por meio de caminhões. A mesma forma de transporte, o rodoviário, também concorre com o ferroviário não só no transporte de cargas como no de passageiros.

Serviços nos quais a existência de sunk-costs seja a menor possível, e que o ingresso e a saída das empresas no mercado não demandem custos muito altos, são os casos típicos nos quais a TMC funcionaria. Para eles, a teoria preconiza a desregulamentação. Exemplos práticos são a coleta de lixo urbana, o transporte aéreo ou ainda o sistema de telefonia a longas distâncias, razoavelmente adequados às condições preconizadas (Johnson et al., 1996).

Baumol, Panzar e Willig (1982) afirmam que, para o caso padrão das curvas de custo médio com formato de $\mathrm{U}$ (U-shaped average cost curves), apesar de raros, há exemplos de sustentabilidade em certas indústrias, ou seja, a determinado preço de mercado a firma é capaz de cobrir seus custos e ainda evitar eventual entrada lucrativa de outra firma. As situações mais comuns, no entanto, são aquelas nas quais a sustentabilidade não é possível.

Entre as contribuições proporcionadas pela TMC figuram, entre outras, a criação de novos e fundamentais conceitos, a afirmação da importância dos sunk-costs e da importância que a competição potencial pode ter na melhoria do desempenho das indústrias. A TMC tem duas limitações básicas, apontadas pelos seus críticos: a hipótese da inexistência de sunk-costs (a maior crítica) e a possibilidade de uma empresa ingressar no mercado antes que a detentora do monopólio possa alterar seus preços.

Ou como apontam Vickers e Yarrow (1997):

"Entretanto nós temos sérias dúvidas sobre a aplicabilidade empírica da teoria da contestabilidade, especialmente para as indústrias maiores [...] ameaças de entrada [de novas firmas no mercado] são normalmente muito desejáveis, mas elas serão impotentes, a menos que sejam suplementadas por políticas 
efetivas de competição que combatam condutas anticompetitivas contra potenciais firmas invasoras, realizadas por parte das firmas monopolistas. Além disso, há um número de mercados e submercados, onde a ameaça de entrada simplesmente não existe e não pode ser criada. Regulamentação direta da firma monopolista é então requerida".

\section{Teoria da Captura}

As hipóteses sobre as quais se baseiam as duas teorias citadas acima, a TMC e a crítica de Demsetz, não são tão abrangentes quanto se poderia desejar, mas há também outra fonte de apoio aos movimentos em prol da desregulamentação dos monopólios. Se aquelas teorias defendem a concorrência como forma de impedir o uso do poder de monopólio, sendo melhor então, em termos de bemestar, haver a desregulamentação, há a corrente que chega a esta conclusão por outra via, afirmando ser a regulamentação ineficaz. É o caso da teoria da captu$\mathrm{ra}$, ou economic theory of regulation.

Segundo Johnson et al. (1996), os estudos voltados para a crítica da regulamentação estatal dos serviços de utilidade pública, e mesmo para o tipo tradicional de concessão, começaram a surgir no início dos anos 60 . Não se aceitava mais a intervenção governamental, para sanar as chamadas falhas de mercado, com a freqüência ocorrida no passado.

A teoria da captura teve seu início na década de 70, com os escritos de Stigler e Jordan, entre outros. Coube a esse último um de seus primeiros esboços, cuja base é a relação entre as empresas monopolistas e os políticos. Estes tendem a procurar obter o que para eles é fundamental e característico de seu comportamento: votos em suas campanhas, e dinheiro, sob várias formas, seja para as suas próprias campanhas, seja para eles mesmos, pessoalmente.

Os políticos tendem a apoiar as regulamentações que lhes dêem o que procuram. Isso, de acordo com a teoria, implicaria que grupos de menor tamanho, porém mais diretamente interessados em determinados assuntos, e com recursos mais vultosos, como é o caso dos produtores, saiam vencedores em relação a conseguir vantagens junto à classe política, quando comparados a grupos maiores, porém menos organizados e com menor conhecimento do assunto, como é o caso dos consumidores. Sindicatos de trabalhadores também podem colocar-se a favor das direções das companhias, visando a conseguir aumentos em seus vencimentos ou mesmo condições mais satisfatórias em seu ambiente laboral.

Os consumidores, por seu lado, costumam ser menos atuantes e possuir uma organização menos efetiva, se comparada à dos sindicatos e à das firmas monopolistas. Desse modo, tendem a ter seus interesses relegados em favor dos 
interesses das empresas. $\mathrm{O}$ contato freqüente entre regulamentador e empresas também tende a levar à corrupção, que pode ocorrer, por exemplo, com ofertas de cargos bem remunerados para os regulamentadores, dentro das empresas regulamentadas, quando eles deixarem seus cargos no setor público.

Logo, a regulamentação serviria, segundo os postulantes da teoria, mais aos interesses dos produtores do que aos interesses dos consumidores, os quais, em princípio, estariam sendo protegidos com a regulamentação da atividade. Os produtores capturariam os que deveriam mandar, isto é, o Governo, geralmente por meio de seus órgãos regulamentadores, e passariam eles a mandar e a tirar proveito da situação. Se para atender aos interesses dos consumidores é melhor a regulamentação dos preços do monopólio em níveis baixos, para a firma detentora desse monopólio é obviamente interessante que os preços de seus produtos sejam fixados em níveis elevados. E isso, segundo vários casos documentados, termina não raramente ocorrendo.

Um dos maiores problemas com relação à influência dos produtores sobre os órgão de regulamentação é o relativo à barragem de firmas interessadas em ingressar no mercado. $\mathrm{O}$ argumento de que, em situações onde ocorram monopólios naturais, uma única firma produz com maior eficiência do que várias, pode ser utilizado indevidamente como argumento pelos produtores para obter a efetiva proibição, por parte do Governo, da entrada de firmas interessadas em produzir nesse mercado, favorecendo a empresa atualmente produtora, ao protegê-la de qualquer competição. Esse argumento das firmas incumbentes é pouco convincente: se realmente houver monopólio natural e a firma monopolista produzir eficientemente, ela terá pouco que temer quanto ao perigo de um hipotético ingresso de outras firmas no mercado, principalmente por estar ela submetida ao controle de preços pelo Governo.

A evolução constante e rápida da tecnologia, principalmente nos dias atuais, tem o poder de transformar o que antes era, de fato, um monopólio natural, numa situação de mercado em que este não mais exista na realidade. Isso é outro aspecto importante para ser considerado. Se o Governo, dando ouvidos à proposta do produtor monopolista, barrar o ingresso de novas firmas no mercado, e essa indústria, por efeito de evoluções tecnológicas, deixar de ser um monopólio natural, ela passará a ser um monopólio apenas por efeito das barreiras impostas pelo Governo, o que seria uma forma de produção anti-econômica e prejudicial aos consumidores.

Em muitos casos, a própria dificuldade em se reconhecer, com satisfatório grau de certeza, os casos em que há ou não a ocorrência efetiva de monopólio natural, faz com que a implementação de barreiras ao ingresso de novas firmas, por parte do Governo, conduza à produção de um bem por uma única firma, quando seria 
mais eficiente, e portanto economicamente mais desejável a produção desse mesmo bem por mais de uma empresa.

Smith (1996) coloca alguns aspectos relacionados à teoria da captura, de acordo com o que ocorreu nos Estados Unidos, principalmente em relação ao setor elétrico, onde, é interessante notar, foi a própria indústria que se empenhou em favor da regulamentação de suas atividades pelo Governo:

"O folclore de que o propósito original da regulamentação era proteger os consumidores dos preços de monopólio está agora sendo desafiado. De 1879 a 1907, empresas elétricas de utilidade pública não eram sujeitas a nenhuma regulamentação de preços. Elas eram obrigadas a obter o direito de operação dos municípios, e a literatura descrevia uma época de competição livre, na qual os municípios concediam o direito a muitas das que solicitavam. Foi a própria indústria, cujos lucros sofreram pelo livre ingresso no mercado, que criou vigorosos lobbies em favor de restrições ao ingresso no mercado e de regulamentação estatal de preços e lucros. Em 1897, Samuel Insull, então presidente da National Electric Light Association [associação] da indústria e um persistente defensor da regulamentação, repetidamente clamava pela criação de licenças exclusivas para as empresas elétricas de utilidade pública e pelo controle de preços do tipo 'lucro justo' a ser realizado pelos Governos de Estado. As regulamentações resultantes serviram para proteger a indústria da competição nos preços, a qual dominou a história no seu início [...] Um estudo do período 1900-20 mostra que os primeiros Estados a adotar a regulamentação foram aqueles nos quais as tarifas de eletricidade e os lucros eram os mais baixos e a produção a mais alta. Além disso, o efeito da regulamentação, durante o período inicial, foi aumentar preços e lucros e reduzir a produção. Estes dados apóiam a hipótese de que a regulamentação foi uma reação das empresas de utilidade pública, desejosas de proteger seus lucros, não uma reação dos consumidores aos preços de monopólio. De fato, os preços monopolistas não foram um problema significativo" (Smith, 1996).

É fácil perceber que a teoria da captura e a teoria do monopólio natural são diametralmente opostas. Esta última, como se viu, diz ser necessária a regulamentação dos monopólios naturais para estes não abusarem de sua privilegiada condição: se agirem livremente, levarão à redução do bem-estar da sociedade, ao imporem preços monopolísticos. Na teoria da captura a afirmação é oposta: a regulamentação e o controle do monopólio, por parte do Governo, é que seriam os responsáveis pela redução do bem-estar, pois os regulamentadores tenderiam a agir segundo os interesses da empresa regulamentada, chegando ao ponto de, em certos casos, perpetuar o monopólio mesmo em condições nas quais este não mais deveria existir naturalmente. 


\section{CONCLUSÃo}

Conclui-se, por meio do estudo das três teorias citadas, e principalmente da análise da experiência norte-americana, que é possível e, em muitos casos desejável, a desregulamentação de algumas indústrias monopolistas brasileiras, desde que elas se enquadrem dentro das precondições determinadas em cada uma das teorias. Os principais requisitos são: a inexistência de sunk-costs, para a teoria dos mercados contestáveis e a simplicidade do trabalho, além da impossibilidade de conluio, para a crítica de Demsetz.

A teoria da captura, por sua vez, nos alerta fortemente para o fato de que a desregulamentação pode ser mais interessante para os consumidores do que a regulamentação governamental, pois o controle do Governo pode levar à perpetuação de situações artificiais de monopólio, ao barrar o ingresso de firmas interessadas em ingressar no mercado, ou então fixar preços e tarifas em níveis elevados, por efeito do conluio entre regulamentadores e firmas monopolistas. Estes fatos reforçam a necessidade de se conhecerem as teorias e de se refletir a respeito de possíveis desregulamentações.

Não se deve, ainda, barrar o ingresso de novas firmas nos mercados, mesmo se determinada empresa monopolista argumentar que produziria melhor, se lhe fosse concedida proteção contra eventuais concorrentes. Isso porque é muito difícil saber quando há realmente monopólio natural em um determinado mercado, e também pelo fato de que inovações tecnológicas freqüentemente fazem com que um monopólio natural deixe de sê-lo.

Sempre que determinada indústria for desregulamentada, é fundamental o seu acompanhamento por órgãos governamentais que implementem políticas antitruste, pois são muito comuns atitudes anticompetitivas, por parte das empresas monopolistas, no sentido de expulsar eventuais firmas concorrentes interessadas em ingressar no mercado, como foi mostrado pelo caso da American Airlines, quando processada pelo Governo americano, ou, antes disso, desencorajá-las a ingressar no mercado.

Uma vez que nem todas as indústrias, como se viu, são suceptíveis de serem desregulamentadas, quando se optar pela regulamentação das empresas monopolistas, deve-se, se possível, fazer uso do sistema de controle de preço. Dos três diferentes tipos que formam este sistema, o mais usual é o preço no nível do custo médio, mas pode-se tentar também o tipo conhecido como tarifação dupla, aconselhado por muitos economistas. 


\section{Referencias Bibliográficas}

BAER, W. J.

FTC perspectives on competition policy and enforcement initiatives in electric power : conference on the new rules of the game for electric power : antitrust \& anticompetitive behavior. [online] Disponível na Internet via WWW. URL: http://www.ftc.gov. Dec. 1997.

BAUMOL, W. J.;

PANZAR, J. C.;

WILLIG, R. D.

Contestable markets and the theory of industry structure. New York : Harcourt Brace Jovanovich, 1982.

\section{CATO INSTITUTE.}

Electricity deregulation : Cato handbook for Congress $-105^{\text {th }}$ Congress. [online] Disponível na Internet via WWW. URL: http:// www.cato.org. 19--.

FARINA, E. M. M. Q.

A teoria dos mercados contestáveis e a teoria da organização industrial. Estudos Econômicos, v. 20, n. 1, p. 05-28, jan./abr. 1990.
FARINA, E. M. M. Q.;

SCHEMBRI, A.

Desregulamentação : a experiência norte-americana. Pesquisa e Planejamento Econômico, v. 20, n. 2, p. 325 352, ago. 1990.

JOHNSON, B. B. et al.

Serviços públicos no Brasil.

São Paulo : Edgard Blücher, 1983.

LEFTWICH, R. H.

O sistema de preços e a alocação de recursos. 6. ed. São Paulo : Pioneira, 1983.

OPPEL JR., R. A.

Deregulation has given power to the power people. The New York Times, 30 Apr. 2000.

ROSEN, H. S.

Public finance. 4. ed. Illinois : Richard D. Irwin, 1995.

SILVA, M. R.

As teorias de desregulamentação de monopólios e as privatizações brasileiras : um enfoque sobre o setor elétrico. São Paulo, 1999. Dissertação (Mestrado) - Universidade Presbiteriana Mackenzie. 
SMITH, V. L.

Regulatory reform in electric power industry. [online] Disponível na Internet via WWW.URL : http:// www.cato.org. Cato Institute : Regulation, v. 19, n. 1, 1996.
THE NEW YORK TIMES.

He freed the airlines. But what to do now? The New York Times, 16 May 1999.

VICKERS, J.;

YARROW, G.

Privatization : an economic analysis. Cambridge : MIT Press, 1997. 